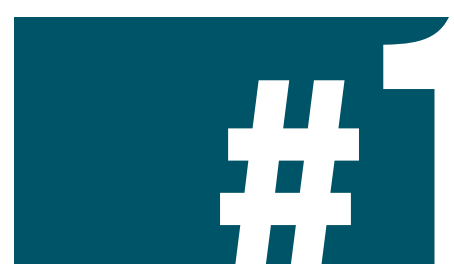

ESPECIAL AMÉRICA LATINA

\title{
LIDERANÇA À BRASILEIRA
}

NA DÉCADA QUE SE ENCERRA, O BRASIL REAFIRMOU SUA INEVITÁVEL LIDERANÇA NA AMÉRICA LATINA, PORÉM MODIFICOU A FORMA DE RELACIONAR-SE COM OS VIZINHOS. ASPECTOS POLÍTICOS DA INTEGRAÇÃO PASSARAM A SER PRIORIZADOS EM RELAÇÃO AOS COMERCIAIS, E O PAÍS ABRIU MÃO DE POSSÍVEIS BENEFÍCIOS ECONÔMICOS EM PROL DA UNIDADE REGIONAL

JULIÁN KAN, professor da Faculdade de Filosofia e Letras da Universidade de Buenos Aires, kanjulian76@yahoo.com.ar

A integração latino-americana experimentou consideráveis mudanças nos últimos anos. A rejeição da Área de Livre Comércio das Américas (Alca), por parte da Venezuela e dos países do Mercosul, em 2005, abriu caminho para a proliferação de novas instâncias de integração, que deixaram de lado propósitos meramente comerciais para dar um passo rumo a outras esferas, como a financeira, a infraestrutural, a de comunicação e a de segurança. A busca de soberania regional intercalase com essas novas esferas, chegando a predominar sobre elas.
Nesse processo, o Brasil teve um papel de destaque, se não o de principal mentor, graças a uma guinada na forma de relacionar-se com sua vizinhança. A grande diferença entre o Brasil das eras Lula e FHC, nesse particular, está no apoio a instâncias de integração com maior autonomia em relação a Washington, e no afrouxamento da retórica do livre comércio.

\section{PRIMEIROS PASSOS}

Desde que chegou ao poder, em 2003, Lula vem solidificando a liderança do Brasil na América Latina ao apostar no fortalecimento da unidade 
regional. Seus primeiros passos envolveram relançar o Mercosul como espaço de coesão regional, de forma a frear a iniciativa norte-americana da Alca. Para tanto, teve de redesenhar a relação bilateral com a Argentina, principal parceiro local. De uma situação marcada por escassa coordenação de decisões macroeconômicas (a exemplo da desvalorização do real em 1999, com efeitos na economia argentina e na relação comercial dos dois países) e pelo também escasso planejamento de uma inserção regional conjunta dos dois países, passou-se a um entendimento no qual têm prevalecido os consensos, ainda que não isentos de tensões. Não por acaso, em outubro de 2003, o primeiro documento firmado em encontros bilaterais com o então presidente argentino, Néstor Kirchner, levou o nome de Consenso de Buenos Aires.

No redesenho da relação com a Argentina, Lula inaugurava sua maneira de construir a liderança regional: buscar o consenso e ceder em prol da unidade. Ao fazer isso, promoveu ações que podem ser entendidas à primeira vista como contraditórias, como, por exemplo, o apoio dado pelo Brasil à entrada da Venezuela no Mercosul, que rendeu a Lula severas críticas. Ou ainda iniciativas que não estavam na sua agenda, mas às quais Lula optou por aceder, como a criação do Banco do Sul, em 2007, a pedido de países vizinhos. Embora o Brasil nem de longe necessitasse dessa instituição, uma vez que conta com o BNDES, o caminho encontrado para construir a liderança envolveu evitar conflitos e apostar na unidade regional, convivendo com esse tipo de aparentes contradições que muitas vezes países líderes tentam aplacar. $\mathrm{Na}$ posse da atual presidente argentina, Cristina Fernández de Kirchner, em dezembro de 2007, Lula afirmou: "Há quem pense que o Brasil pode buscar seus caminhos por conta própria. Nós acreditamos que trabalhar junto com a América do Sul nos fortalece". Sempre que aparece um conflito, a invocação do multilateralismo e da integração é uma constante.

\section{NÃO À ALCA}

Um momento-chave para a integração latino-americana recente foi a oposição à Alca, por parte do Mercosul e da Venezuela do presidente Hugo Chávez. Essa unidade regional no rechaço à iniciativa norteamericana de livre-comércio, concretizada na IV Cúpula das Américas, em Mar del Plata, na Argentina, em 2005, pode ser considerada outro marco para a construção das novas formas de integração, e para a liderança brasileira na região.

A partir dessa oposição, Lula pôde se concentrar em sua tarefa de solidificar a unidade regional convivendo com contradições, por exemplo, ao qualificar de "soberana" a nacionalização da produção de gás e petróleo decretada pelo presidente boliviano Evo Morales em 2006, em que se viam afetados fortes interesses econômicos brasileiros. Apostou em novas instâncias de integração, como a Unasul (União das Nações SulAmericanas), e conviveu com a Venezuela, convertida em outro atorchave que persegue projetos, como a Alba (Aliança Bolivariana para as Américas), distantes da realidade brasileira. Lula, por sinal, tem-se posicionado como defensor de Chávez sempre que este é acusado de autoritarismo. Também aceitou, em 2009, revisar os termos da exploração da usina hidrelétrica de Itaipu, tradicionalmente desfavoráveis ao Paraguai.

\section{UNASUL E AUTONOMIA}

Apostar na Unasul - uma instância regional autônoma, por meio da qual 


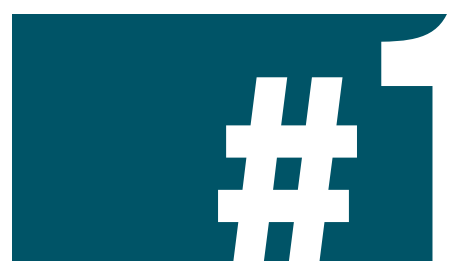

ESPECIAL AMÉRICA LATINA

LIDERANÇA Ả BRASILEIRA

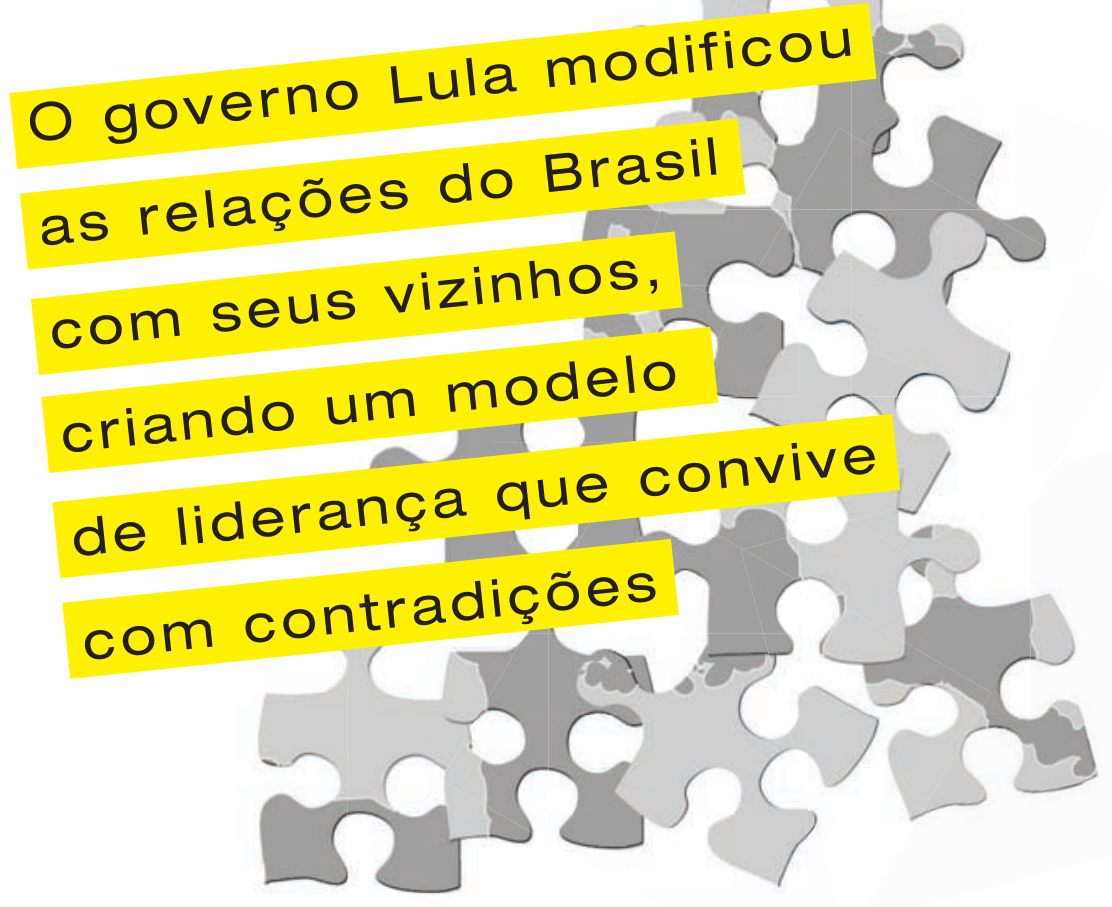

se podem dirimir conflitos sem consultar a Organização de Estados Americanos (OEA), sob forte influência dos EUA - foi um fator-chave. O Brasil já tinha tentado contribuir como mediador em conflitos entre as Forças Armadas Revolucionárias da Colômbia (FARC) e o governo do presidente colombiano Álvaro Uribe, e também em conflitos entre Equador e Colômbia, desatados, em 2008, com o assassinato de um dos líderes da guerrilha colombiana, Raúl Reyes, em solo equatoriano. Mas a projeção regional do país passa a contar com novas ferramentas, outorgadas pela Unasul. Diferentemente da sua antecessora, a
Confederação das Nações SulAmericanas (CSN), e das tentativas de fusão esboçadas por Fernando Henrique Cardoso entre a Comunidade Andina de Nações (CAN) e o Mercosul, a Unasul não tem no aspecto comercial o eixo articulador da integração. Sua aposta é política, e aqui outra vez se reconhece o modelo de liderança brasileiro com unidade regional.

Nesse processo de afirmação da autonomia regional, Lula retomou projetos que estavam engavetados. Um deles, que teve como artífice o ministro brasileiro da Defesa, Nelson Jobim, foi a criação do Conselho de Defesa Sul-Americano (CDS), órgão de defesa regional que veio superar o Tratado Interamericano de Assistência Recíproca (TIAR), criado sob forte influência dos EUA, no marco da guerra fria - mais uma instância de integração que transcendeu a esfera comercial, ao privilegiar a esfera política da segurança e da soberania.

\section{INTEGRAÇÃO À BRASILEIRA}

As causas da inevitável liderança regional do Brasil podem ser atribuídas ao tamanho de sua economia, ao seu lugar no cenário mundial como parte do G20 e dos BRICs, entre vários outros fatores. Porém, o exposto neste artigo permite observar que essa liderança do Brasil também tem se construído mediante a busca de unidade regional, por meio de um maior diálogo com seus vizinhos, cedendo ou compartilhando muitas vezes o papel de líder, ou mesmo abrindo mão de possíveis benefícios econômicos em prol das demandas dos seus vizinhos. No âmbito latino-americano, na primeira década do século, o Brasil não se impôs, mas dialogou e buscou o consenso, além de privilegiar aspectos políticos em relação aos comerciais. Isso configura, sem dúvida, uma mudança de ângulo em relação à década anterior. 